\title{
Explosive Cladding with Gold
}

\section{PROTECTIVE LININGS FOR AUTOCLAVE SYSTEMS}

\author{
Gisela Bechtold and Immanuel Michael \\ Gesellschaft für Kernforschung mbH, Karlsruhe, West Germany
}

\section{and Rolf Prümmer}

Fraunhofer-Gesellschaft für Angewandte Forschung eV, Pfinztal/Karlsruhe, West Germany

Explosive cladding is an important addition to the established methods of bonding one metal to another. This article reviews the factors governing bonding by this process and then describes the successful lining of nickel-chromium steel tubular autoclaves for pressurised water reactors with a corrosion resistant layer of gold.

In autoclave systems in which chemical reactions are being carried out it is essential to ensure that corrosion does not occur. While it may not be possible to construct such vessels from a single material having all the required properties, it is quite possible to combine materials so that the major part of the equipment has the required strength for operation at high pressures and temperatures but, having a less than satisfactory resistance to corrosion, is protected by a layer of another material that has good corrosion resistance even though it has low mechanical strength.

In pressurised water reactors corrosion of the inner surfaces clearly cannot be tolerated, but a coating of gold provides the necessary protection. Experimental work with the explosive cladding of thin layers of gold to the inner walls of tubular autoclaves has established that firmly adherent and pore-free coatings can be successfully applied by this method.

\section{The Principles of \\ Explosive Cladding}

As with roll bonding, explosive cladding is a solid phase process in which the detonation impacts a high velocity to the coating material, known as the flyer plate. As this collides with the parent body it undergoes a rapid retardation and an extremely high pressure is generated in both plates in the area of impact. Provided that the angle of collision is carefully chosen, new surfaces are generated under conditions of hydrodynamic flow and the two plates enter into such intimate contact that metallic bonding takes place.

Techniques for explosive cladding, mostly in a plane arrangement, have been described by several authors $(1,2,3)$ but the arrangement used for lining the inside of a tube is shown in Figure 1. Here a tube of the lining material, coated with a thin uniform layer of explosive, is arranged concentrically within the tube to be clad, the gap between them being one to three times the thickness of the lining. When ignition has been started at one end-simultaneously round the perimeter-an annular detonation wave moves axially along the tube so that the inner lining is accelerated to the plate velocity $\mathrm{Vp}$ and impacts on the surface to be clad at the angle of collision $\beta$. To achieve bonding certain conditions must be fulfilled; $\beta$ must exceed a value depending on the materialusually around $10^{\circ}$-and the collision velocity must not exceed 120 per cent of the velocity of sound in the materials to be bonded. The collision velocity $V_{I K}$ in this arrangement is equal to the detonation velocity $V_{D}$, and it thus depends solely on the nature of the explosive, however the plate velocity $\mathrm{Vp}$ is

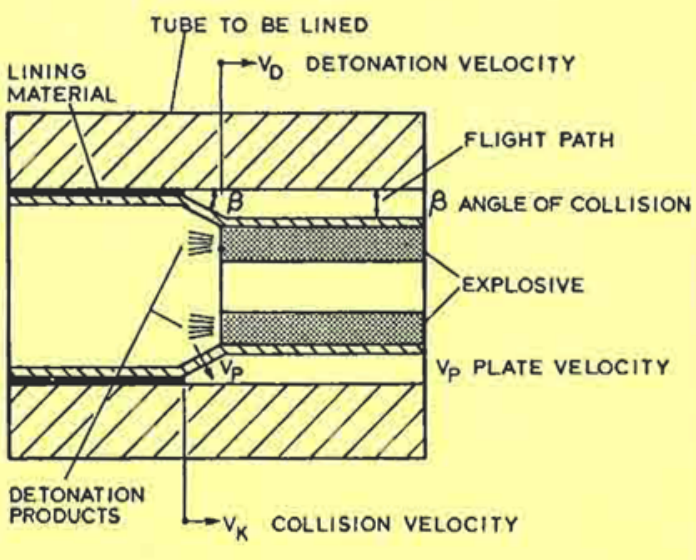

Fig. 1 An arrangement for explosive cladding the inner walls of tubes. The lining material is in the form of a thin tube placed concentrically and having a thin coating of explosive material 


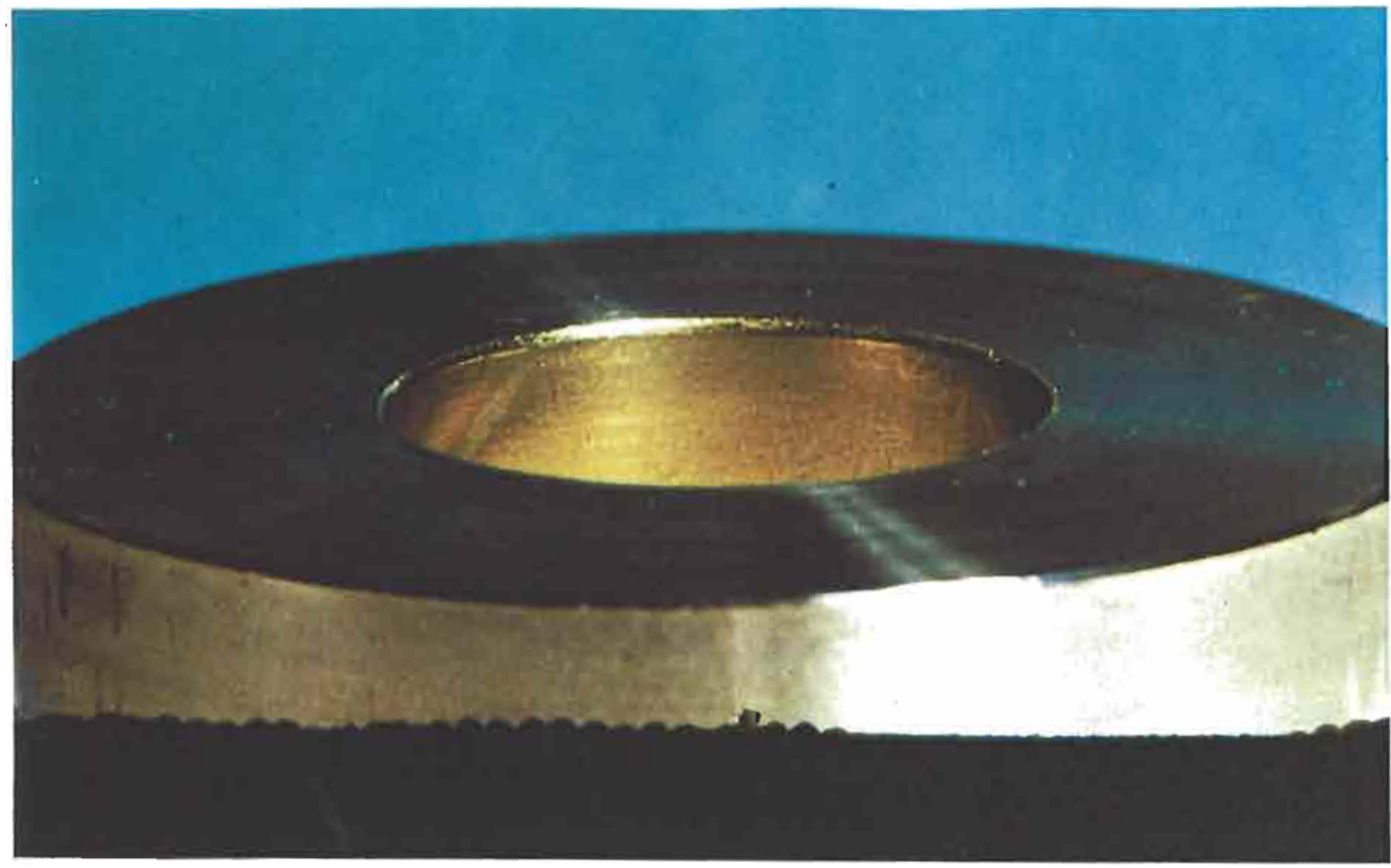

Fig. 2 . The end view of a nickel-clurome steel tubular autoclave, $400 \mathrm{~mm}$ in length, with a gold lining applied by explosive cladding. This technique has important potentialities in the protection of chcmical reaction vessels

dependent on the ratio of mass of the explosive'to the mass of the flyer plate. For the arrangement in Figure 1

$$
\frac{V p}{V_{D}}=2 \sin \frac{\beta}{2}
$$

When thin sheets of gold are to be applied by explosive cladding this can only be carried out with a supporting plate as the thin sheet might rupture, while the flyer plate must also have a minimum mass per unit area because otherwise such thin layers of explosive would be used that detonation could not be ensured.

The gold sheet can be attached to the support plate either by means of an adhesive or by roll bonding. In this investigation a glued bond was used to join a $2 \mathrm{~mm}$ thick aluminium tube to the sheet of gold, as shown in Figure 3. Where the gold overlapped, the surfaces had to be kept very clean, while to ensure successful cladding a gap of at least twice the sheet thickness was provided.

To establish the optimum conditions for bonding gold to nickel-chrome steels tests were first carried out on flat specimens. It was found that the following conditions gave good bonding: a collision velocity $\mathrm{V}_{\mathrm{K}}$ of 1250 metres per second, with a collision angle ranging from 10 to $13^{\circ}$ and a plate velocity $\mathrm{Vp}$ of 210 to 270 metres per second.

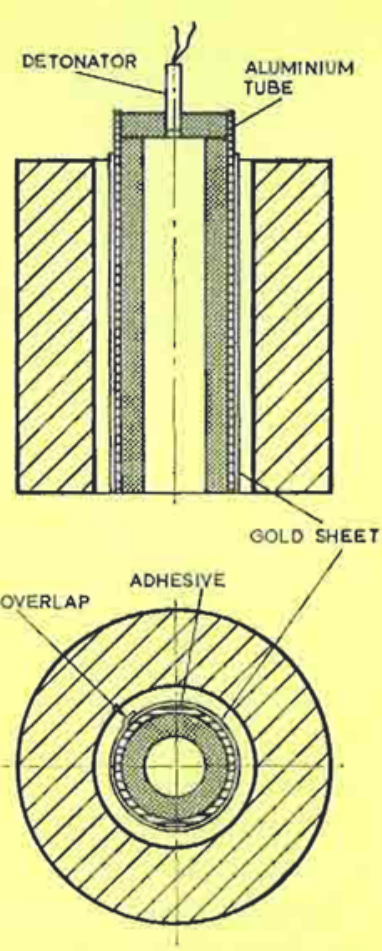

Fig. 3 The test arrangement used for the internal cladding with gold of nickel-chrome steel tubes. Instead of a tube, a sheet of gold is used attached to an aluminium tube for support 


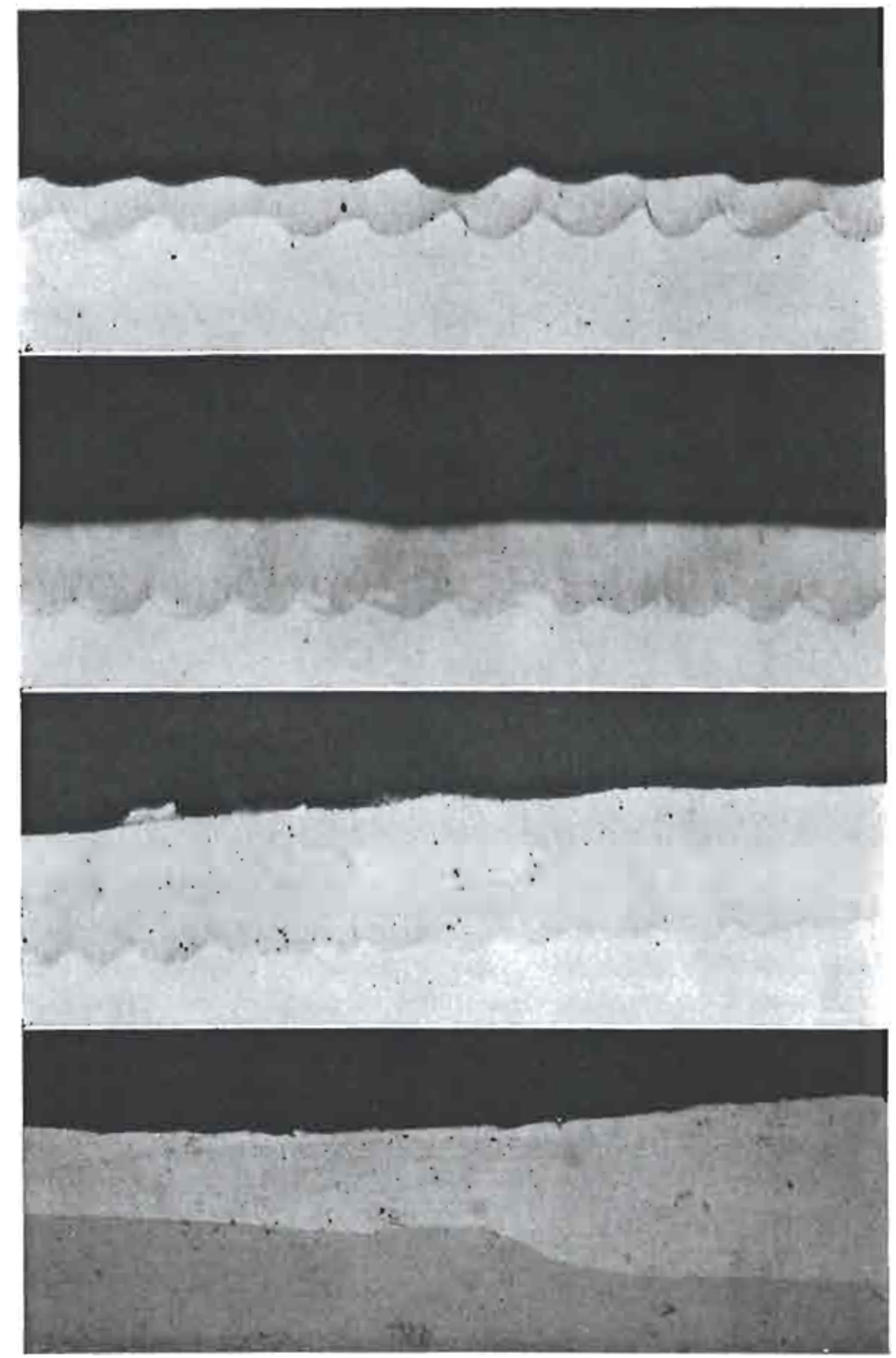

Fig. 4. Photomicrograples of the gold clad steel contact zone $\times 50$

(a) Gold thickuess $50 \mu \mathrm{m}$;

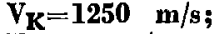
$V_{p}=240 \mathrm{~m} / \mathrm{s} ; \beta=12.7^{\circ}$

(b) Gold thickness $100 \mu \mathrm{m}$; $V_{K}=1250 \mathrm{~m} / \mathrm{s}$; $V_{p}=240 \mathrm{~m} / \mathrm{s} ; \beta=11.7^{\circ}$

(c) Gold thickness $150 \mu \mathrm{m}$; $\mathrm{V}_{\mathrm{K}}=1250 \mathrm{~m} / \mathrm{s}$; $V_{p}=216 \mathrm{~m} / \mathrm{s} ; \beta=10.9^{\circ}$

(d) Transition from single to double gold thickmess at the overlap

Higher collision velocities than 1250 metres per second and greater collision angles than $13^{\circ}$ produced bonded layers characterised by very pronounced waviness, while at plate velocities greater than 300 metres per second the sheet was usually found to rupture.

Typical compound layers for three thicknesses of sheet-50, 100 and $150 \mu \mathrm{m}$-are shown in the micrographs of Figure 4.

With the $50 \mu \mathrm{m}$ sheet the waviness protrudes almost to the surface, and sheets of this thickness or less are clearly unsuitable for explosive cladding.

That a good metallic bond is obtained in the area of overlap of the edge of the gold sheet is demonstrated in the micrograph of Figure $4 \mathrm{~d}$, which clearly shows the transition from single to double thickness and that the superimposed gold sheets are completely welded to each other.
To return to the problem of waviness, the ratio

$$
\frac{\text { Wave height }}{\text { Wave length }}=0.25
$$

was established by A. A. Deribas and his colleagues (4), and in the tests with the three thicknesses of gold sheet this same ratio was obtained. However, the relationship established by these workers for the wave length of the serrations

$$
\lambda=26 \cdot d \cdot \sin ^{2} \frac{\beta}{2}
$$

whereby the wave length is directly proportional to the thickness of the flyer plate, was found to be in agreement with our work. Taking the total thickness of the compound aluminium/gold flyer plate an appreciably higher value of $0.3 \mathrm{~mm}$ was obtained, while taking the thickness of the gold sheet above gave a figure only about one half of theoretical. It 


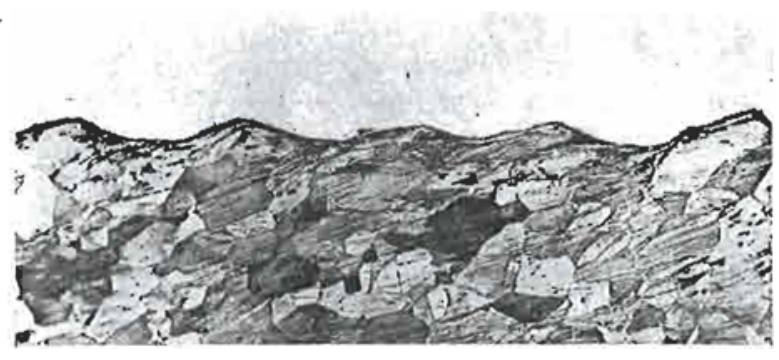

Fig. 5 Photomicrograph of gold clad nickel.

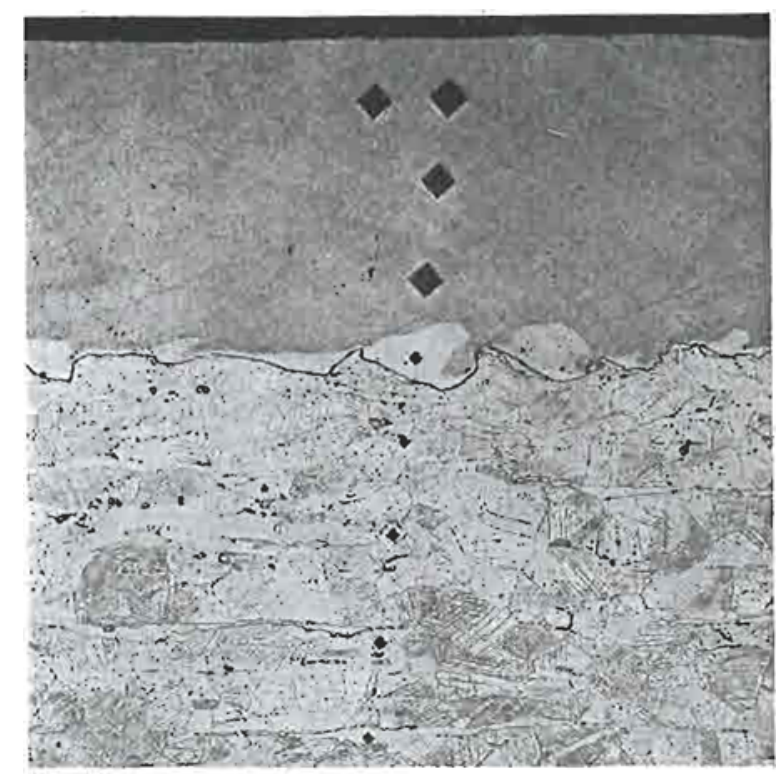

successfully to clad large tubular autoclaves with pore-free and firmly adherent gold linings. These are $400 \mathrm{~mm}$ in length with a wall thickness of 20 $\mathrm{mm}$ and are to be used in pressurised water reactors.

Figure 2 on page 35 shows an end view of the upper section of one such vessel. The use of a gold tube has been shown to be unnecessary, as simple gold sheet, more readily available commercially, can be satisfactory welded at the overlaps.

\section{References}

1 G. R. Cowan and A. H. Holtzmann, F. Appl. Phys,, 1963, 34, 928

2 R. Prümmer, Z. Werkstofftechnik/F. Materials Technology, 1972, 3, (6), 305-310

3 F. Jähn, R. Prummer and Ch. Liesner, Metall., 1974, 28, (1), 957-960

4 A. A. Deribas et al, Investigations of Changes in the Zones of Collision by Explosive Joining of Metals, Symposium on Dynamic Pressure, Paris 1967, 351-354

The technique described here has been used

\section{New Thick Film Gold Conductors}

The extensive range of gold-based thick film conductor preparations now available to the user was recently reviewed by $\mathrm{Dr} \mathrm{R} . \mathrm{H}$. Caley in this journal (Gold Bulletin, 1976, 9, (3), 70-75). Steady improvements and modifications to these products have assisted significantly in enhancing the performance and reliability of microelectronic circuitry.

Two further products have now been announced by the Electronic Materials Division of $\mathrm{Du}$ Pont. One, identified as gold conductor 9910 , is specifically designed for applications where aluminium wire bonding is to be used in high reliability hybrid microcircuits and in multilayer structures for interconnecting arrays of monolithic integrated circuits. Test data, using ultrasonic bonding, have shown that this composition provides superior aluminium wire bonding with high pull strengths after ageing at $150^{\circ} \mathrm{C}$ for long periods, The resistivity obtained is from 3 to 5 milliohms per square, and it is reported to have good adhesion to 96 to 99.5 per cent alumina and beryllia substrates together with good solderability with the usual germanium-gold, tin-gold and tin-leadindium solders.

The second new product, 9791 , is a mixed bonded material providing good adhesion both to the substrate and to a new dielectric composition. It provide resistivities of 2 to 5 milliohms per square, with resolution of 5 mil lines and vias for high density interconnections. It is recommended for eutectic die, gold wire and beam-lead bonding applications. 